\title{
Epistemic beliefs of non-STEM majors regarding the nature of science: Where they are and what we can do
}

Shannon D. Willoughby, and Keith Johnson

Citation: American Journal of Physics 85, 461 (2017); doi: 10.1119/1.4979654

View online: http://dx.doi.org/10.1119/1.4979654

View Table of Contents: http://aapt.scitation.org/toc/ajp/85/6

Published by the American Association of Physics Teachers

\section{Articles you may be interested in}

AN APOLOGY FROM THE FORMER ASSOCIATE EDITOR

American Journal of Physics 85, 405 (2017); 10.1119/1.4981790

Rotating and rolling rigid bodies and the "hairy ball" theorem

American Journal of Physics 85, 447 (2017); 10.1119/1.4979343

On the origin of energy: Metaphors and manifestations as resources for conceptualizing and measuring the invisible, imponderable

American Journal of Physics 85, 454 (2017); 10.1119/1.4979538

A quantitative analysis of the chain fountain

American Journal of Physics 85, 414 (2017); 10.1119/1.4980071

2017 Oersted Medal Presentation: The changing face of physics and the students who take physics American Journal of Physics 85, 409 (2017); 10.1119/1.4980008

A smooth trip to Alpha Centauri: Comment on "The least uncomfortable journey from A to B" [Am. J. Phys. 84(9) 690-695]

American Journal of Physics 85, 469 (2017); 10.1119/1.4981789

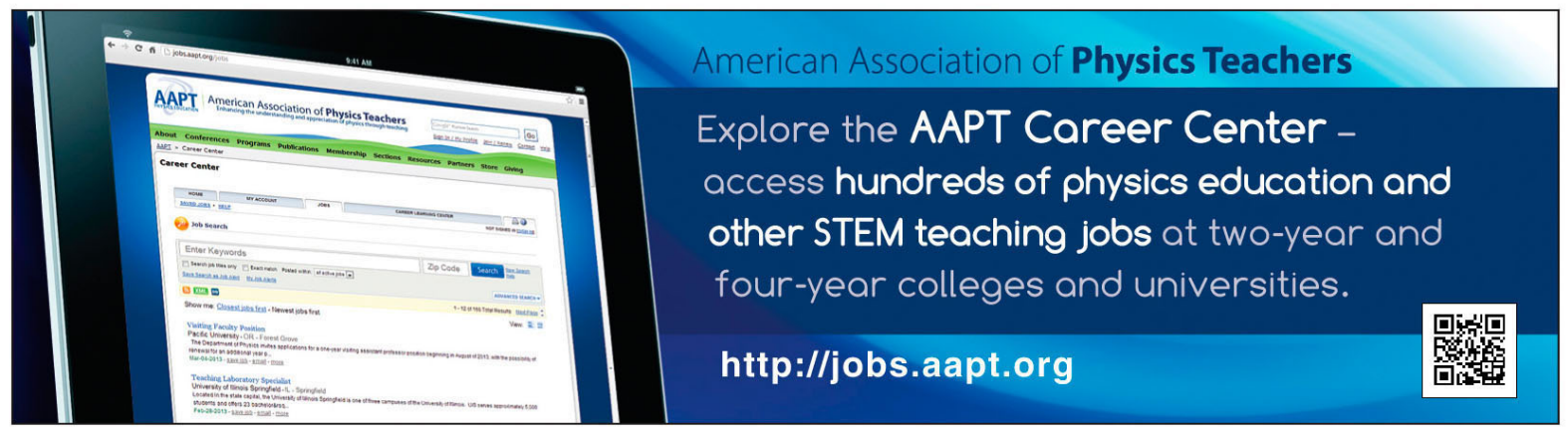




\title{
PHYSICS EDUCATION RESEARCH SECTION
}

The Physics Education Research Section (PERS) publishes articles describing important results from the field of physics education research. Manuscripts should be submitted using the web-based system that can be accessed via the American Journal of Physics home page, http://ajp.dickinson.edu, and will be forwarded to the PERS editor for consideration.

\section{Epistemic beliefs of non-STEM majors regarding the nature of science: Where they are and what we can do}

\author{
Shannon D. Willoughby a) and Keith Johnson \\ Department of Physics, Montana State University, Bozeman, Montana 59717-3840
}

(Received 3 May 2016; accepted 21 March 2017)

\begin{abstract}
Students enrolled in introductory astronomy at a mid-sized land grant institution were surveyed at the start and end of each semester for three years regarding their epistemic beliefs about the physical sciences. After collecting data for two years in the control (baseline) course, the course was revised to include regular discussions of the nature of science, practice identifying pseudoscientific claims, and practice with metacognition. Survey data on epistemic beliefs were collected for one more academic year after the course was revised. This work details how the course was structured during the baseline and revised portions of the study. Data from both portions of the study are analyzed as a whole as well as broken down by gender. Negative trends seen in the baseline data are mostly eradicated in the revised portion of the course. The data analysis motivates a discussion of why including content regarding the nature of science should be integrated in classes geared toward nonscience majors. () 2017 Author(s). All article content, except where otherwise noted, is licensed under a Creative Commons Attribution 4.0 Unported License. [http://dx.doi.org/10.1119/1.4979654]
\end{abstract}

\section{BACKGROUND AND OVERVIEW}

Experts in STEM fields have long been concerned about the general publics' lack of scientific literacy, with a myriad of national science organizations pledging to better engage non-scientists. For example, NASA states that, "Using programmatic tools and resources, the Science Mission Directorate is building strategic educational and public outreach partnerships to enhance the Nation's formal education system and contribute to the broad public understanding of science, technology, engineering, and mathematics (STEM)." ${ }^{11}$ The American Astronomical Society is more specific: "The Society promotes broad interest in astronomy, which enhances science literacy and leads many to careers in science and engineering." "2 Also discussed at a national level in a report to department leaders regarding goals for "Astronomy 101 " is the stated aim to leave students “... Interested in and more equipped to follow scientific arguments in the media and more confident of their own critical faculties." 3 A group of astronomy education experts have stated that, "A worthy course goal would be for your [astronomy] students to value the pursuit of science in society as equal to the pursuit of art, ethics, and innovation." that all of these diverse groups of stakeholders are strategizing about how to improve science literacy and epistemologies related to science demonstrates the importance of this issue.

Introductory astronomy is taken by at least 250,000 students each year ${ }^{5}$ and is often the only science course that non-science majors will take while pursuing an undergraduate degree. Nationally about $85 \%$ of students taking introductory astronomy are not STEM majors. ${ }^{6}$ As scientists and teaching professionals, we understand that the general populace really does need to have a basic understanding of how science works because it can lead to better decision making. For example, should city water supplies be fluoridated? What can households do locally about global warming? Should children be vaccinated? Each of these questions can best be analyzed through the lens of scientific understanding, both at personal and societal levels. As science instructors, we have limited opportunities to ask students to examine their epistemic beliefs about science and to motivate them to see why it matters in their everyday lives. We should not hope to improve our students' scientific literacy if their underlying epistemic beliefs toward science are rudimentary.

Epistemic beliefs can be defined as beliefs about what it means to learn and how knowledge is constructed. Research into student epistemologies and scientific literacy has shown that non-science majors who take general education science courses have degraded attitudes toward science upon completion of these courses. ${ }^{7-9}$ (We note that these authors use the term "attitudes" while we prefer the more accurate "epistemologies.") Exit interviews and final exam questions in these studies revealed that many students also leave these courses concerned that the ability to learn science is an innate trait that cannot be honed. These types of lower-level science courses typically include very little explicit instruction about the nature of science, practice identifying pseudoscientific claims, or practice in metacognition.

Research related to students' epistemic beliefs about the natural sciences has been done in the past, including works by Bates, Duncan, Elby, Kalman, Lising, May, and Redish. ${ }^{7,9-14}$ Duncan and Elby both used the same instrument as in the current study, the Epistemological Beliefs 
about the Physical Sciences Survey (EBAPS) ${ }^{15}$ and their works are discussed further below.

Three studies in particular are similar to the current work, except that the populations studied were students taking introductory physics, not astronomy. Because these student populations tend to be quite dissimilar, we note these results are important, but cannot necessarily be directly translated to non-STEM majors.

Almost two decades ago, the Maryland Physics Expectations Survey was developed and validated. ${ }^{9}$ The researchers found that students and experts had very different views about physics courses, and that students' attitudes in all six schools tested tended to degrade over the course of a semester. They mention that, "Much of what we do in introductory classes does not address the hidden curriculum of improved understanding and attitudes." Some twenty years later this is still true in many introductory science classes.

Recently, Kalman et al. ${ }^{12}$ published a study suggesting that using a multi-pronged approach toward improving introductory physics students' epistemic beliefs may be effective. Their interventions included pre-class reading with a metacognitive reflective piece and active learning through cognitive dissonance in the classroom. Their article also includes a thorough literature review pertaining to the study of epistemologies in general, as well as a discussion of the instrument they developed and used-the Discipline Focused Epistemological Beliefs Questionnaire.

Elby studied student epistemologies using the EBAPS in both high school and college level physics courses. Also using a relatively intensive set of interventions, Elby found that students in the study did not show changes in their epistemic beliefs about either the use of evidence based reasoning in science nor their belief that the ability to learn science is an innate trait. The author did find that students had positive changes along other measures within the EBAPS including how scientific knowledge is structured and metacognition, plus the overall measure (measures are described below in Table I).

Duncan, in a study that would go on to motivate our own work, used the EBAPS instrument in his astronomy courses. ${ }^{7}$ Comparing the results of both a control and a test group (which had nature of science material integrated), he found that students in the control (unchanged) astronomy course answered the survey questions quite differently than students in the test course. Answers to six of the thirty EBAPS questions had statistically significant differences between the two samples, with those in the test course having more sophisticated responses. This study suggests that embedding material about the nature of science and teaching how to identify the differences between science and pseudoscience may lead to more expert-like understanding of science within the test group. However, several issues do arise with this work, one of which was suggested in his article: "We hope that our interesting results will prompt others to try similar experiments in their courses, some of which are more precisely matched." As is also pointed out in the article, the classes in this study do not represent true test and control courses because the control course was the first in a two-sequence course and the test course was the second. Furthermore, the courses were taught by two different instructors.

Our investigation is akin to that of Duncan's but has overcome the shortcomings present in his study. In this current work, we collected EBAPS data for three years in Astronomy 110 . It is a single semester course taught each fall and spring semester with typical enrollments of 600 and 400 , respectively. Student demographics do not vary much from semester to semester with the majority of students being non-STEM majors, native to the state, and slightly more than half male. Lastly, the course was consistently taught by the same instructor, during both baseline and revised portion of the study. The overarching curiosity driving our research was whether or not simple modifications (focused on the nature of science) to a course can be enough to prevent the decay in student epistemic beliefs regarding science, as has been more commonly observed across the country. Using this motivator as our guide, we have asked and addressed the following research questions:

1. How do students' epistemic beliefs about science change over the course of a semester, as indicated by our baseline (unchanged) course?

2. How do students' epistemic beliefs about the sciences change after some basic course modifications and how does this compare to the changes seen in the unmodified course?

3. Do we see differences in epistemic beliefs when considering gender and do course modifications effect students of either gender differently?

Table I. Description of EBAPS axes.

1. Structure of scientific knowledge. Is [science] a coherent, conceptual, highly structured, unified whole? Expert views along this axis align with a view that the sciences are indeed coherent and unified.

2. Nature of knowing and learning. Does learning science consist mainly of absorbing information? Or, does it rely crucially on constructing one's own understanding by working through the material actively, by relating new material to prior experiences, intuitions, and knowledge, and by reflecting on and monitoring one's own understanding? Thus, this axis gauges metacognition. Most experts agree that new information must be built into the web of our pre-existing knowledge.

3. Real-life applicability. Are scientific knowledge and scientific ways of thinking applicable only to restricted spheres such as the classroom or the laboratory?... These items tease out students' views of the applicability of scientific knowledge as distinct from the student's own desire to apply science to real life, which depends on the student's interests, goals, and other non-epistemological factors. Professional scientists realize that thinking scientifically can be useful in everyday situations.

4. Evolving knowledge. This dimension probes the extent to which students navigate between the twin perils of absolutism and extreme relativism. Experts avoid either peril. A score of four on this axis represents not falling into either trap. Other authors (Refs. 11 and 29) suggest this axis can also be viewed as measuring the extent to which students think that science is either tentative or settled.

5. Source of ability to learn. Is being good at science mostly a matter of fixed natural ability? Or, can most people become better at learning (and doing) science? As much as possible, these items probe students' epistemological views about the efficacy of hard work and good study strategies, as distinct from their self confidence and other beliefs about themselves. Education researchers typically agree that anyone can learn science and that it is not a fixed ability. 
These research questions have been addressed by administering the EBAPS as a pre-test and a post-test in four semesters of the baseline astronomy course and two semesters of the redesigned course, then analyzing matched pre- and post-test scores. The consistency of the course over these semesters helps isolate the effect course modifications alone may have on students' beliefs. To this end, we think that the findings we present will speak to a broader audience than just introductory astronomy instructors.

Our interest in exploring the role that gender may be playing stemmed from the results of research elsewhere. Studies in which the data are parsed by gender have shown that there is a gender gap in prior content knowledge and a gap in gains on concept inventories such as the Test of Astronomy Standards, ${ }^{16}$ the Astronomy Diagnostic Test, ${ }^{17}$ and the Lunar Phases Concept Inventory. ${ }^{18,39}$ When considering epistemic beliefs, there have also been reported gender differences as measured by the Colorado Learning About Science Survey ${ }^{8}$ as well as the Thinking about Science Survey Instrument. ${ }^{19,20}$

\section{METHODS}

Epistemic beliefs, or beliefs about knowledge and learning, are not always conscious for students, which can make these beliefs difficult to measure. Although forced choice instruments are one of several ways to collect data on these beliefs, we acknowledge that within the scope of this research we are collecting snapshots of students' epistemologies about the physical sciences. Use of a forced choice instrument has the advantages of being relatively quick to administer and score. We can test students' epistemic beliefs at the start of the semester and again at the end of the semester in order to measure change. Student interviews ${ }^{13}$ and analysis of student reflective writing ${ }^{14}$ provide qualitative information in how students think about thinking and learning, and this is part of our future work discussed at the end of this paper.

There exist several other popular instruments that measure student epistemologies outside those mentioned in the studies above. The Attitudes and Approaches to Problem Solving survey ${ }^{21}$ was initially developed for, and tested on, physics graduate students. Another recent assessment is called the Thinking About Science Survey Instrument. ${ }^{19}$ Over the span of 60 items this valid and reliable instrument probes the relationship between students' views of science and what they believe the role of science within society to be.

The Colorado Learning Attitudes about Science Survey $(\text { CLASS })^{8}$ was based on the popular Maryland Physics Expectations ${ }^{9}$ and Views About Science Survey ${ }^{22}$ questionnaires. The CLASS is also a valid and reliable instrument that has been administered at many institutions and used in several studies. ${ }^{10,23,24}$ Questions on this instrument also center on doing and understanding physics homework problems. While originally focusing on physics, versions emphasizing biology and chemistry now exist as well. A thorough review of these types of instruments going back to 1905 is provided in Lederman ${ }^{25}$ and a database of surveys and associated articles can be found on the Physport website. ${ }^{26}$

Our instrument of choice for this study was the EBAPS. The authors of the EBAPS survey suggest that the instrument is both valid and reliable. ${ }^{15}$ We completed our own test of reliability following a method similar to Perkins et al. ${ }^{8}$ Because the demographics of the student population taking this particular course do not vary much from semester to semester, one test of the survey's reliability is to compare pre-test scores for each of the semesters the survey was administered. By performing an H-test on the four semesters of pre-test baseline data we have, we found that indeed the pre-test scores are not statistically significant from semester to semester, with $\chi^{2}(3)=0.455, p=0.929$ for the overall measure. In addition, H-tests along each axis also suggested no statistically significant differences. (An H-test is basically an F-test for non-parametric data.)

The EBAPS itself is relatively short at 30 questions, and measures student epistemologies regarding science along five axes as well as an overall measure. Each of the five nonorthogonal axes is described in Table I, as per the authors of the instrument. ${ }^{15}$ While many other instruments focus on a specific topic (such as those previously mentioned), the EBAPS is geared more toward the general sciences; hence our commitment to the EBAPS (version 2) for the purposes of our research project. This survey also has been used in other research projects, including a Ph.D. thesis by Muchoney, ${ }^{27}$ as well as articles published by Palomar, ${ }^{28}$ Duffy, ${ }^{29}$ and Elby. ${ }^{11}$ We note that each of the aforementioned publications surveyed much smaller numbers of students compared to our research project and none of them included effect sizes.

Over six semesters we administered the EBAPS in our Astronomy 110 on the first day of the course and again during the last week of classes. Students completed the EBAPS survey on five option bubble sheets. The EBAPS website ${ }^{15}$ includes a spreadsheet that converts students' bubble sheet choices to numerical answers, then groups questions along each of the five axes. Each axis ranges from zero to four, with a score of zero indicating epistemic beliefs that are novice-like, and a score of four indicating beliefs that are consistent with an expert-like scientific epistemology. Pretest and post-test scores were matched for each student to directly compare student-by-student how this snapshot of their views changed from the start of the semester to the end. Unmatched data were discarded. When comparing the pretest scores to the post-test scores along each axis a Wilcoxin signed-rank test was used. Effect sizes were calculated as well, using the Cohen's $d$ method with pooled standard deviations. A discussion of effect sizes can be found in works by Coe, Kirk, and Rice. ${ }^{30-32}$

\section{COURSE DETAILS}

The Astronomy 110 course is geared toward non-science majors and fulfills a general education science requirement. The demographics of students enrolled in this course are similar to the demographics of the overall student population at the University. At the time of the study, the course had approximately 1000 students enrolled per academic year at a medium-sized land grant institution in the northern United States. Students taking this course were $42.1 \%$ male, $39.7 \%$ female, and $18.2 \%$ did not report their gender. Overall, the average population in the course was $45.5 \%$ freshmen, $31.2 \%$ sophomores, $12.7 \%$ juniors, and $10.6 \%$ seniors. The majority of the students are from in-state and, although we did not ask students for their racial identity, the vast majority are Caucasian. (As a whole, the institution consists of $84 \%$ self-reported Caucasian students, 54\% are in-state and 54\% are male.)

An active learning environment ${ }^{33}$ was created during each class meeting, but consistent reinforcement of topics regarding the nature of science were not major parts of the course. 
The scientific method was introduced during the first week of class, then not directly addressed again. Major topics included naked eye/historical astronomy, cosmology, stellar evolution, and the solar system. In each 200 student section of the course, students formed learning teams each consisting of four students and these learning teams persisted throughout the semester. Students used personal response systems (clickers) each day, lecture tutorials were used during most class periods, and exams consisted of both individual and group portions. Students also completed reflective writing assignments several times during the semester. Outside of class students were asked to read from the text before coming to lecture, but no homework was assigned.

\section{REVISED COURSE}

We reveal to you now the results of our baseline data, as revisions to the course were driven by the analysis of this data. After 4 semesters of EBAPS data collection from our unmodified Astronomy 110 course, we found that students were experiencing a decline in epistemic belief structure pertaining to axes two (nature of knowing and learning), four (evolving knowledge), five (source of ability to learn), and the overall measure. The decay in overall student epistemic belief structure is consistent with results across the nation. However, because the EBAPS measures specific areas, or axes, of epistemic beliefs we were able to focus revisions to these areas. Initial changes to the course have been centered on affecting axes two and four, with axis five to be addressed in future work.

When the class was revised an active learning environment was still upheld, personal response systems were still used, and learning teams were still employed. The changes implemented involved developing material focused on the nature of science, as well as explicitly relating course material to the nature of science. Any new material was added to the course in lectures that had not previously filled the entire time allotted to each class meeting. Reflective writing and other metacognitive tasks were also included to a larger degree than during the baseline portion of the study, with the goal of positively affecting axis two.

We similarly targeted student epistemic beliefs along axis four. Specifically, we addressed issues related to both absolutism and relativism. In practice, these two perils can be thought of as students treating scientific evidence as being set in stone (absolutism) or purely opinion-based (relativism). In order to address issues with absolutism, we discussed a multitude of ways in which understanding in astronomy has changed over the millennia. Classroom discussions combating absolutism include historical changes in solar system models, cosmology, and understanding the scale of the universe. To directly combat relativism, we suggested that often there are clear lines of evidence to suggest why certain things occur. For example, the seasons could be caused by Earth's proximity to the Sun, but there is compelling evidence against this. These lines of reasoning are carefully covered in class so students are exposed to the fact that science does indeed change over time (absolutism is not a valid way to consider scientific discoveries), and that sometimes one concept does a superior job of explaining phenomena; not all opinions are equal.

In general, we have asked students to search for links between their everyday lives and science, to practice metacognition, to appreciate the tentativeness of science, and to learn in various ways beyond that of simple note taking. Primary course changes are outlined below.

\section{A. Teaching the nature of science}

Because it affects all aspects of epistemic beliefs (axes two and four included), our primary goal was to make the nature of science an integral part of the course. By regularly discussing how science works and by asking students to see how science is related to their lives, we fundamentally changed our approach to teaching non-science majors. There are several definitions of the nature of science, and we adopt the definition used by Lederman: "[the nature of science] refers to the values and assumptions inherent to the development of scientific knowledge." 25 Because this topic is fairly broad, we focus specifically on several key aspects: asking students to apply the scientific method, discussing the role of skepticism in scientific discovery, and finding connections to science in their daily lives. Research suggests that the nature of science and how the scientific method is applied needs to be discussed and practiced multiple times in order for students to better understand the concepts ${ }^{25,34}$ and in our revised course, content relating to the nature of science was included at least once each week.

We begin on the first day of class by introducing the scientific method in colloquial terms: first, observations are made, then patterns are noticed. An explanation is imagined and from this explanation predictions are made. The loop is then closed as further observations are made to determine whether or not the prediction is consistent with the observation. Eventually, we want to communicate the explanation and predictions to other people so they can also work to determine if the predictions are consistent with their observations. Over the course of a semester the scientific method as defined above is reinforced through a variety of topics, such as moon phases, seasons, and HR diagrams. It is important to focus on each aspect of the scientific method in turn; this is to reduce cognitive overload, ${ }^{35}$ or to allow for students to "chunk" the information. ${ }^{36}$ The goal is to eventually have students understand the scientific method as a coherent whole.

Being skeptical goes hand in hand with applying the scientific method, because once an explanation has been developed for some phenomenon and predictions made, this information can be shared and other people can confirm or deny if the predictions are consistent with their observations. Three to four times during the semester we ask students to complete a worksheet called Science in the Media. Depending on the assignment, students are asked to find an article published by any online source, a major newspaper, or from either a.edu or.gov website. The first Science in the Media assignment is to read and analyze a website claiming the Apollo moon landings were a hoax. ${ }^{40}$ The worksheet asks students to consider whether or not personal beliefs are driving the hoax claims, if they think the website is reliable, and whether or not they agree with the conclusions drawn by the author. It also asks students to look for websites that refute the claims, and to determine where the preponderance of evidence points. Worksheet questions were discussed with an information literacy specialist before being implemented, and are included in Appendix A.

All nature of science material in our revised course was aimed to have the greatest effect on both axes two and four, as well as the overall measure of the EBAPS. In this regard, 
one of our goals in including nature of science material was to share with students the understanding that learning science is a self-constructed process dependent on metacognitive activities. Furthermore, every student has the opportunity to apply science to naked eye astronomy, to practice skepticism, and relate course material to concepts they are most likely already familiar with. Lastly, by acquiring a better understanding of what science is and how it is done we believe our students will find a healthier balance between the perils of absolutism and relativism. (For any specifics or questions regarding course changes and the nature of science, we encourage readers to contact the primary author of this paper.)

\section{B. Metacognition}

Of particular interest is the extent to which we can probe students' metacognition, i.e., how they monitor their own thinking and understanding. Metacognition, or "... the notion of thinking about one's own thought or thinking process" 41 is a crucial component that enables students to undergo any conceptual change. ${ }^{42-44}$ If a student does not focus on metacognitive activities during the learning process, they are unlikely to overcome any previous misconceptions. Metacognitive actions frequently provide learners with information that influences the selection and use of cognitive strategies. $^{45,46}$

Research suggests that metacognition is a skill that requires practice. ${ }^{47}$ To this end we have created several assignments that guide students to consider and analyze their own understanding. These activities include use of exit tickets, exam wrappers, writing their own exam questions, and creating visual representations. A thorough outline of these activities and what they encompass can be found in Appendix B. Assessing metacognition is no trivial task, as it is not directly observable and often involves many types of knowledge. Examples of valid instruments assessing solely metacognition include the Learning and Study Strategies Instrument (LASSI) ${ }^{48}$ and the Metacognitive Awareness Inventory. ${ }^{49}$ Both of these instruments consist of over 50 items, and only test metacognition. Axis two of the EBAPS allows us to measure, and therefore monitor, student metacognition.

\section{ANALYSIS AND CONCLUSIONS}

The research questions addressed in this study were:

1. How do students' epistemic beliefs about science change over the course of a semester, as indicated by our baseline (unchanged) course?

2. How do students' epistemic beliefs about the sciences change after some basic course modifications and how does this compare to the changes seen in the unmodified course?

3. Do we see differences in epistemic beliefs when considering gender and do course modifications effect students of either gender differently?

Question one was explored through a statistical analysis of the two years of baseline data, displayed in Table II. The second question was explored through a statistical analysis of the revised course data, shown in Table III. Comparison of the two aforementioned tables reveals differences in the revised course compared to the baseline course. Finally,
Table II. Baseline pre-test and post-test averages, ${ }^{\mathrm{a}} n=913$.

\begin{tabular}{lcccccc}
\hline \hline & Pre-test & St. dev. & Post-test & St. dev. & Effect size & $p$-value \\
\hline Axis 1 & 2.25 & 0.459 & 2.27 & 0.485 & 0.054 & 0.055 \\
Axis 2 & 2.60 & 0.521 & 2.52 & 0.556 & 0.148 & $0.000 \downarrow$ \\
Axis 3 & 2.87 & 0.692 & 2.82 & 0.739 & 0.062 & 0.211 \\
Axis 4 & 2.59 & 0.782 & 2.52 & 0.768 & 0.101 & $0.023 \downarrow$ \\
Axis 5 & 3.01 & 0.669 & 2.82 & 0.750 & 0.267 & $0.000 \downarrow$ \\
Overall & 2.61 & 0.356 & 2.54 & 0.407 & 0.168 & $0.000 \downarrow$ \\
\hline \hline
\end{tabular}

ascores range from 0 to 4 , and effect sizes were calculated using Cohen's $d$ with pooled standard deviations.

question three was explored by breaking down the data by gender. Not all students provided information about gender, hence the numbers for these data are slightly smaller than the overall data. Statistics of the baseline data broken down by gender are detailed in Table IV, and for the revised course in Table $\mathrm{V}$.

In the two years of baseline data, we found that students' epistemic beliefs had statistically significant declines along axes two, four, and five, as well as in the overall measure (as can be seen in Table II). Cohen ${ }^{37}$ would state that the effect sizes displayed in the tables suggest that each of the drops were "small" (around 0.2), while the $p$-values indicate that the drops were indeed measurable. In Duncan's work, ${ }^{7}$ he found that students in his control course had statistically significant decreases from pre-test to post-test on six EBAPS questions, four of which are aligned with axis five. These declines pertaining to axis five for both Duncan's study and our own may warrant further investigation into student epistemologies regarding their source of ability to learn.

Analysis of the revised semesters revealed that students had a statistically significant drop only along axis five, as seen in Table III. There were no measurable drops along axes two, four, or the overall measure. Focused course modifications seem to have resulted in a stop to the downward slide we saw in the two years of baseline data and are further reflected in the fact that there were no measurable changes along the overall measure in the revised portion of the course. Ideally, we aim to create a significant increase in epistemic beliefs with our revisions; however, simply preventing deterioration is the current goal. We believe that including more of these modifications would continue to aid epistemological improvement, and future interviews will also expand our understanding of our students' epistemic belief structure. In comparing the baseline and revised courses, effect sizes seem to become smaller overall thus supporting our case that the extent of epistemological

Table III. Revised course pre-test and post-test averages, ${ }^{\text {a }} n=548$.

\begin{tabular}{lcccccc}
\hline \hline & Pre-test & St. dev. & Post-test & St. dev. & Effect size & $p$-value \\
\hline Axis 1 & 2.30 & 0.488 & 2.34 & 0.475 & 0.072 & 0.116 \\
Axis 2 & 2.61 & 0.521 & 2.56 & 0.540 & 0.094 & 0.055 \\
Axis 3 & 2.87 & 0.718 & 2.91 & 0.689 & 0.050 & 0.340 \\
Axis 4 & 2.64 & 0.838 & 2.56 & 0.773 & 0.105 & 0.063 \\
Axis 5 & 3.10 & 0.647 & 2.97 & 0.701 & 0.185 & $0.000 \downarrow$ \\
Overall & 2.65 & 0.367 & 2.62 & 0.391 & 0.074 & 0.192 \\
\hline \hline
\end{tabular}

ascores range from 0 to 4 , and effect sizes were calculated using Cohen's $d$ with pooled standard deviations. 
Table IV. Baseline pre-test and post-test averages, ${ }^{\mathrm{a}} n=354$ for females and $n=366$ for males.

\begin{tabular}{lcccccc}
\hline \hline & Pre-test & St. dev. & Post-test & St. dev. & Effect size & $p$-value \\
\hline Axis 1 Female & 2.25 & 0.428 & 2.26 & 0.450 & 0.041 & 0.350 \\
Axis 1 Male & 2.27 & 0.478 & 2.31 & 0.522 & 0.091 & 0.054 \\
Axis 2 Female & 2.64 & 0.515 & 2.58 & 0.523 & 0.122 & $0.036 \downarrow$ \\
Axis 2 Male & 2.57 & 0.536 & 2.50 & 0.571 & 0.119 & 0.054 \\
Axis 3 Female & 2.79 & 0.668 & 2.78 & 0.694 & 0.017 & 0.999 \\
Axis 3 Male & 2.94 & 0.723 & 2.89 & 0.775 & 0.067 & 0.211 \\
Axis 4 Female & 2.61 & 0.763 & 2.58 & 0.737 & 0.041 & 0.419 \\
Axis 4 Male & 2.61 & 0.789 & 2.49 & 0.782 & 0.147 & $0.001 \downarrow$ \\
Axis 5 Female & 3.01 & 0.690 & 2.86 & 0.741 & 0.199 & $0.001 \downarrow$ \\
Axis 5 Male & 3.04 & 0.653 & 2.80 & 0.749 & 0.344 & $0.000 \downarrow$ \\
Overall Female & 2.61 & 0.346 & 2.57 & 0.381 & 0.111 & 0.073 \\
Overall Male & 2.62 & 0.367 & 2.55 & 0.423 & 0.184 & $0.000 \downarrow$ \\
\hline \hline
\end{tabular}

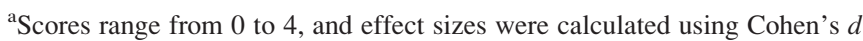
with pooled standard deviations.

deterioration has indeed dwindled. For reasons outlined by Gene Glass in a meta-analysis of social research, ${ }^{38}$ we value this comparison between effect sizes over interpretations of individual effect size outcomes when possible. Regarding individual effect size interpretations, Glass goes so far as to state that "There is no wisdom whatsoever in attempting to associate regions of the effect-size metric with descriptive adjectives such as 'small,' 'moderate,' 'large,' and the like." 38

Both baseline and revised course data are shown broken down by gender in Tables IV and V, respectively. As can be seen from the baseline gender data, the drop along axis two can be primarily attributed to females, and drops along axes four and the overall measure can be attributed primarily to males. The drop along axis five, which is the largest drop of all, is seen for both males and females in the baseline portion of the study. In the revised portion of the course, male students showed a drop along axis five only. Female students did not show statistically significant changes along any axis.

Another attitude survey, the CLASS (discussed above) has shown differences between males and females when

Table V. Revised Course pre-test and post-test averages, ${ }^{\text {a }} n=227$ for females and $n=248$ for males.

\begin{tabular}{lcccccc}
\hline \hline & Pre-test & St. dev. & Post-test & St. dev. & Effect size & $p$-value \\
\hline Axis 1 Female & 2.34 & 0.455 & 2.35 & 0.504 & 0.024 & 0.664 \\
Axis 1 Male & 2.29 & 0.518 & 2.635 & 0.465 & 0.115 & 0.116 \\
Axis 2 Female & 2.66 & 0.499 & 2.63 & 0.515 & 0.065 & 0.374 \\
Axis 2 Male & 2.58 & 0.526 & 2.54 & 0.564 & 0.066 & 0.507 \\
Axis 3 Female & 2.84 & 0.702 & 2.89 & 0.661 & 0.075 & 0.312 \\
Axis 3 Male & 2.91 & 0.720 & 2.97 & 0.712 & 0.081 & 0.205 \\
Axis 4 Female & 2.70 & 0.802 & 2.59 & 0.756 & 0.133 & 0.142 \\
Axis 4 Male & 2.62 & 0.848 & 2.54 & 0.770 & 0.194 & 0.278 \\
Axis 5 Female & 3.02 & 0.691 & 2.93 & 0.709 & 0.129 & 0.077 \\
Axis 5 Male & 3.014 & 0.616 & 3.01 & 0.695 & 0.192 & 0.014 \\
Overall Female & 2.66 & 0.357 & 2.63 & 0.395 & 0.082 & 0.279 \\
Overall Male & 2.65 & 0.365 & 2.63 & 0.399 & 0.045 & 0.748 \\
\hline \hline
\end{tabular}

${ }^{\text {a }}$ Scores range from 0 to 4 , and effect sizes were calculated using Cohen's $d$ with pooled standard deviations. measuring their attitudes toward science. ${ }^{8}$ Specifically, that female students showed "less expert-like attitudes on statements in the 'real world connections,' 'personal interest,' 'problem solving confidence,' and 'problem solving sophistication' categories and a bit more expert-like on some 'sensemaking/effort' type statements." ${ }^{8}$ Our baseline findings are consistent with those findings. Based on the results of our revised course, we conclude that we are having a positive effect on our female students. We also note that the instructor for this course is female. We took care in the course to regularly state that everyone can learn astronomy and we also regularly asked our students to be active participants in their learning using gender neutral language.

As discussed above, axis five measures the extent to which students believe that learning science is a fixed or malleable trait. We have consistently seen drops along this axis during all six semesters of the study. Although we have focused predominantly on axes two and four thus far in the two semesters of the revised course, the persistence of axis five is of worthy note. Recent work by Aguilar et al. ${ }^{50}$ suggests that targeted writing interventions may have a positive effect on students' beliefs about their own abilities to learn science. This would be an interesting intervention to pursue, although we have not done so yet.

The approach utilized in our revised course is one we believe to be widely applicable for use in science courses geared toward non-STEM majors. We have found that our student population does not vary much from semester to semester, in terms of their demographics as well as their incoming epistemic beliefs about the sciences. The population of students we have studied is similar to the overall US population of college students, so our results should hold widely. Also, the materials we have developed and philosophies we have applied are simple to implement and do not necessarily require large chunks of class time. It is our hope that these tools will be used in myriad science classes, because we can, and indeed we should, do a better job of teaching science to our future parents, teachers, and politicians.

Overall, we have found that, compared to the baseline, our revised course has caused student epistemologies to stop declining in two specific areas and the overall measure: the nature of knowing and learning, and the extent to which students fall into either peril of absolutism or relativism. We have also found that students in each of the six semesters of our study show declines in epistemologies regarding their ability to learn, i.e., they are more apt to believe that their ability to learn science is the result of natural ability and not hard work. In the revised portion of the course, this degradation is found to be statistically significant among male students only, with female students showing no changes along any axes. We note that ideally our students would leave Astronomy 110 with improved epistemic stances, and acknowledge that as a field we may have to settle for a steadiness in those epistemologies in the short term.

\section{FUTURE WORK}

This research shows that students' epistemic beliefs about the physical sciences can be influenced by regular and explicit inclusion of nature of science materials within the classroom. That students' epistemic beliefs can hold steady while taking an introductory astronomy course and not decline as has been seen in our baseline data and other 
national studies. We continue to teach the revised version of the course and in our future work we will look more specifically at the relationships between formal reasoning ability, student attitudes, and metacognition. During the 2016-2017 academic year, we will conduct interviews with students enrolled in Astronomy 110 regarding axis five, as this axis is the one that has seen consistent declines throughout the study. Our hope is that these interviews will help guide future course modifications in an attempt to improve student efficacy regarding study habits and hard work.

\section{ACKNOWLEDGMENTS}

The authors would like to thank Librarian Sheila Bonnand for her input and advice on the Science in the Media Worksheets, and the Statistical Consulting and Research Services Group at MSU Bozeman for their advice on the statistical analysis in this research.

\section{APPENDIX A: WORKSHEET QUESTIONS}

Read an online article from any.edu or.gov source. The article should be about science, but does not need to be about astronomy in particular.

\section{Source:}

Topic:

Summary of content:

Comments related to source:

Is it reliable?

Are personal beliefs driving the claim?

Do you agree with the conclusions drawn by the author? Why or why not?

Can you find a website/source that makes the opposite claim?

Link/source:

Is this site reputable? How did you decide this?

Do other sources agree with this source? Most, some or none?

Where does the preponderance of evidence point?

\section{APPENDIX B: METACOGNITION ACTIVITIES}

\section{Exit tickets}

Before beginning the exam review (which typically occurs two days before the exam), we ask students to jot down one concept they are still struggling with, known as an exit ticket or the muddiest point. ${ }^{51}$ Using the course learning goals as their guide, students think about what they do and do not understand and why, thus engaging in metacognition (axis two), which can help focus their studies. These slips of paper are collected and read by the instructors so we can glean insight into what students struggle with most. Answers are collated and inform teaching for the next semester. A second technique we employ occurs during review sessions, when students are asked to write their own exam questions. Research in a psychology course ${ }^{52}$ found that students who wrote their own test questions (either multiple choice or essay style) performed better on two out of three tests compared to students who wrote no questions. Even if the quality of the questions is not high, it appears this is an effective study strategy for students. We also collect and read these.

\section{Exam wrappers}

After each of the first two midterms, we ask students to complete an exam wrapper. ${ }^{47}$ In this reflective writing assignment, students discuss how they prepared for the exam-alone or with a group, creating flash cards or going over course materials. Students are then asked to go over their exam and look for any patterns in the questions they missed. Was one topic not understood? Did they perform poorly just on the multiple choice or just on the short answer? Finally, students are asked how they might change their study habits for the next exam. The goal of these exercises is to again have students engage in metacognition (axis two) to improve their understanding before the exam, then reflect on their exam preparation and performance after their exams have been graded and handed back.

\section{Visual representations of knowledge}

Finally, as a regular part of the course students are asked to create visual representations of their understanding, including the following examples. By drawing out a pictorial representation of an in-class demonstration, students will process information differently than by just taking notes 36,53 and hence must practice metacognitive strategies (axis two) to translate between their notes and the representation they are creating.

A demonstration of seasonal asterisms at the front of the classroom utilized an Earth globe, around which several students acted as stars. Following this, students are asked to draw a picture in their notes that shows why Leo is a seasonal asterism. During the lecture on stellar evolution, students are asked to create a concept map describing how stars evolve and showing how the evolutionary sequence depends on the mass of the star. After taking down this information in notes, students can create a visual representation of the entire process and sum up their knowledge in a visual way. Finally, students are asked to create a Venn diagram comparing Jovian and Terrestrial planets during the section on the solar system. Using class time to let students sift through information is one way we demonstrate to our students that tasks related to metacognition are worthwhile and can increase conceptual understanding.

\footnotetext{
${ }^{a) E l e c t r o n i c ~ m a i l: ~ s h a n n o n . w i l l o u g h b y @ m o n t a n a . e d u ~}$

${ }^{1}$ The NASA Science program strategy can be found at $<\mathrm{http}: / /$ science.nasa. gov/researchers/education-public-outreach/strategy $>$.

${ }^{2}$ The American Astronomical Society mission and vision statement is available at $<$ http://aas.org/governance/aas-mission-and-vision-statement $>$.

${ }^{3}$ B. Partridge and G. Greenstein, "Goals for 'Astro 101': Report on workshops for department leaders," Astron. Educ. Rev. 2(2), 46-89 (2003).

${ }^{4}$ T. Slater and J. Adams, "What topics are taught in introductory astronomy courses?," Phys. Teach. 39, 52-55 (2001).

${ }^{5}$ A. Fraknoi, "The state of astronomy education in the US," Astron. Soc. Pacific Conf. Ser. 89, 9-25 (1996).

${ }^{6}$ G. Deming and B. Hufnagel, "Who's Taking Astro 101?," Phys. Teach. 39, 368-369 (2001).

${ }^{7}$ D. Duncan and L. Arthurs, "Improving student attitudes about learning science and student scientific reasoning skills," Astron. Educ. Rev. 11, 010102 (2012).

${ }^{8}$ W. K. Adams, K. K. Perkins, N. S. Podelefsky et al., "New instrument for measuring student beliefs about physics and learning physics: The Colorado learning attitudes about science survey," Phys. Rev. Spec. Top.: Phys. Educ. Rev. 2, 010101 (2006).

${ }^{9}$ E. F. Redish, J. M. Saul, and R. N. Steinberg, "Student expectations in introductory physics,” Am. J. Phys. 66, 212-224 (1998).
} 
${ }^{10}$ S. Bates, R. Galloway, C. Loptson, and K. Slaughter, "How attitudes and beliefs about physics change from high school to faculty," Phys. Rev. Spec. Top.: Phys. Educ. Res. 7, 020114 (2011).

${ }^{11}$ A. Elby, "Helping physics students learn how to learn," Am. J. Phys. Suppl. 69(7), S54-S64 (2000).

${ }^{12}$ C. S. Kalman, M. Sobhanzadeh, R. Thompson, A. Ibrahim, and X. Wang, "Combination of interventions can change students' epistemological beliefs,” Phys. Rev. ST Phys. Educ. Res. 11, 020136 (2015).

${ }^{13}$ L. Lising and A. Elby, "The impact of epistemology on learning: A case study from introductory physics,” Am. J. Phys. 73, 372-382 (2005).

${ }^{14}$ D. B. May and E. Etkina, "College physics students epistemological selfreflection and its relationship to conceptual learning," Am. J. Phys. 70, 1249-1258 (2002).

15“"The idea behind ebaps," < http://www2.physics.umd.edu/elby/EBAPS/ idea.htm $>$.

${ }^{16} \mathrm{~S}$. J. Slater, "The development and validation of the test of astronomy standards (TOAST)," Journal of Astronomy \& Earth Sciences Education 1(1), 1-22 (2014)

${ }^{17}$ G. L. Deming, "Results of the astronomy diagnostic test national project," Bull. Am. Astron. Soc. 33, 1424 (2001).

${ }^{18}$ A. Rudolph, E. Prather, G. Brissenden et al., "A national study assessing the teaching and learning of introductory astronomy Part II: The connection between student demographics and learning," Astron. Educ. Rev. 9, 010107 (2010).

${ }^{19}$ W. Cobern, Scientific Literacy and Cultural Studies Project (Kalamazoo, MI, 2000).

${ }^{20}$ C. Wallace, E. Prather, and B. Mendelsohn, “Astro 101 students' perceptions of science: Results from the 'thinking about science survey instrument'," Astron. Educ. Rev. 12, 010101 (2013).

${ }^{21}$ A. Mason and C. Singh, "Surveying graduate students attitudes and approaches to problem solving," Phys. Rev. Spec. Top.: Phys. Educ. Res. 6, 020124 (2010); available at https://www.physport.org/assessments/ assessment.cfm?I1/460\&A1/4AAPS.

${ }^{22}$ I. Halloun and D. Hestenes, "Interpreting VASS dimensions and profiles for physics students," Sci. Educ. 7, 553-577 (1998).

${ }^{23}$ J. de la Garza and H. Alarcon, "Assessing students' attitudes in a college physics course in Mexico," in Physics Education Research Conference 2010, PER Conference (Portland, Oregon, 2010), Vol. 1289, pp. 129-132.

${ }^{24}$ M. Milner-Bolotin, T. Antimirova, A. Noack, and A. Petrov, "Attitudes about science and conceptual physics learning in university introductory physics courses," Phys. Rev. Spec. Top.: Phys. Educ. Res. 7, 020107 (2011).

${ }^{25}$ N. Lederman, "Students' and teachers' conceptions of the nature of science: A review of the research," J. Res. Sci. Teach. 29, 331-359 (1992).

${ }^{26}$ See the Physport website here http://www.physport.org for an assortment of instrument surveys and articles.

${ }^{27}$ D. Muchoney, "The implementation of an interactive engagement model of instruction in high school physics," Ph.D. thesis, The Robert Morris University (2008), p. 71.

${ }^{28}$ B. Palomar, B. Cruz, and J. Rogel, "Science and non-science education students' images and epistemological beliefs toward physics learning," in International History, Philosophy and Science Teaching Asian Regional Conference (Taipei, Taiwan, 2014).

${ }^{29} \mathrm{G}$. Duffy and S. Chance, "Improving engineering students design skills in a project-based learning course by addressing epistemological issues," in 40th SEFI Conference (Thessaloniki, Greece, 2012).

${ }^{30} \mathrm{R}$. Coe, "It's the effect size, stupid. WhateEffect size is and why it is important," Paper presented at the Annual Conference of the British Educational Research Association, University of Exeter (2002).
${ }^{31}$ R. Kirk, "Practical significance: A concept whose time has come," Educ. Psychol. Meas. 56, 746-759 (1996).

${ }^{32}$ M. Rice and G. Harris, "Comparing effect sizes in follow-up studies: ROC, Cohen's d and r,” Am. Psychol. Law Soc. 29, 615-620 (2005).

${ }^{33}$ S. Freeman, S. Eddy, M. McDonough et al., "End of Lecture: Active learning increases student performance across the STEM disciplines," Proc. Natl. Acad. Sci. U.S.A 111, 8410-8415 (2014).

${ }^{34} \mathrm{D}$. Allchin, Teaching the Nature of Science (SHiPS Education Press, Saint Paul, MN, 2013), pp. 3-27.

${ }^{35}$ J. Sweller, "Cognitive load during problem solving: effects on learning," Cogn. Sci. 12, 257-285 (1988).

${ }^{36}$ W. McKeachie and M. Svinicki, "How to make lectures more effective," McKeachie's Teaching Tips (2006), pp. 58-73.

${ }^{37}$ J. Cohen, Statistical Power Analysis for the Behavioral Sciences (L. Erlbaum Associates, Hillsdale, NJ, 1988).

${ }^{38}$ G. Glass, B. McGaw, and M. Smith, "Definition and interpretation of effect size," Meta-Analysis in Social Research (1981), pp. 99-106.

${ }^{39}$ R. Lindell and J. P. Olsen, "Developing the lunar phases concept inventory," in Physics Education Research Conference 2002, PER Conference (Boise, Idaho, 2002).

${ }^{40}$ The following website http://www.ufos-aliens.co.uk/cosmicapollo.html is a prime example of standard arguments from a moon landing hoax supporter.

${ }^{41}$ M. Hennessey, "Metacognitive aspect of students reflective discourse: implications for intentional conceptual change teaching and learning," in Intentional Conceptual Change, edited by G. M. Sinatra and P. R. Pintrich (2003), pp. 103-132.

${ }^{42}$ P. Hewson, M. Beeth, and N. Thorley, "Teaching for Conceptual Change," International Handbook of Science Education (1998), pp. 199-218.

${ }^{43}$ M. Sackes, "The role of cognitive, metacognitive, and motivational variables in conceptual change: Preservice early childhood teachers conceptual understanding of the cause of lunar phases," Ph.D. thesis, Ohio State University (2010).

${ }^{44}$ H. Vilppu, M. Mikkil-Ermann, and I. Ahopelto, "The role of regulation and processing strategies in understanding science text among university students," Scandinavian J. Educ. Res. 57, 246-262 (2013).

${ }^{45}$ P. Pintrich, C. Wolters, and G. Baxter, "Assessing metacognition and selfregulated learning," available online at $<$ http://digitalcommons.unl.edu/ burosmetacognition/3/> (2000).

${ }^{46}$ A. Heikkila and K. Lonka, "Studying in higher education: Students' approaches to learning, self-regulation, and cognitive strategies," Stud. Higher Educ. 31, 99-117 (2006).

${ }^{47}$ S. Ambrose, M. Bridges, M. DiPietro et al., How Learning Works: Seven Research Based Principles for Smart Teaching (Jossey-Bass Publishers, San Francisco, CA, 2010) pp. 188-216.

${ }^{48}$ See http://www.hhpublishing.com/_assessments/lassi/ for access to, and information on, LASSI.

${ }^{49}$ This brief inventory, https://www.harford.edu/ /media/PDF/Student-Services/ Tutoring/Metacognition\%20Awareness\%20Inventory.ashx, provides a quick means by which to gauge ones metacognitive ability.

${ }^{50}$ L. Aguilar, G. Walton, and C. Wieman, Phys. Today 67(5), 43-49 (2014).

${ }^{51}$ T. Angelo and K. Cross, "Muddiest Point," Classroom Assessment Techniques: A Handbook for College Teachers (Jossey-Bass Publishers, San Francisco, CA, 1993), pp. 154-158.

${ }^{52}$ P. Foos, Teach. Psychol. 1677, 77-78 (1989).

${ }^{53}$ J. Novak, Learning, Using and Creating Knowledge: Concept Maps as Facilitative Tools in Schools and Corporations (Taylor \& Francis, Milton Park, England, 2009). 